This is an electronic reprint of the original article. This reprint may differ from the original in pagination and typographic detail.

\author{
Author(s): Tuononen, Heikki; Suontamo, Reijo; Valkonen, Jussi; Laitinen, Risto S.; Chivers, \\ Tristram
}

Title: $\quad$ Electronic Structures and Molecular Properties of Chalcogen Nitrides Se2N2 and SeSN2

Year: $\quad 2005$

Version:

Please cite the original version:

Tuononen, H., Suontamo, R., Valkonen, J., Laitinen, R. S., \& Chivers, T. (2005). Electronic Structures and Molecular Properties of Chalcogen Nitrides Se2N2 and SeSN2. Journal of Physical Chemistry A, 109(28), 6309-6317.

https://doi.org/10.1021/jp052502a

All material supplied via JYX is protected by copyright and other intellectual property rights, and duplication or sale of all or part of any of the repository collections is not permitted, except that material may be duplicated by you for your research use or educational purposes in electronic or print form. You must obtain permission for any other use. Electronic or print copies may not be offered, whether for sale or otherwise to anyone who is not an authorised user. 


\section{Electronic Structures and Molecular Properties of Chalcogen Nitrides $\mathrm{Se}_{2} \mathrm{~N}_{2}$ and $\mathrm{SeSN}_{2}$.}

Heikki M. Tuononen, ${ }^{*}, \dagger$ Reijo Suontamo,${ }^{\dagger}$ Jussi Valkonen, ${ }^{\dagger}$ Risto S. Laitinen, ${ }^{*}{ }^{\dagger}$ and Tristram Chivers ${ }^{\S}$

Departments of Chemistry, University of Jyväskylä, P. O. Box 35, FIN-40014 Jyväskylä, Finland; University of Oulu, P. O. Box 3000, FIN-90014 Oulu, Finland; and University of Calgary, 2500 University Drive N. W., Calgary, Alberta, Canada T2N 1N4.

* Authors to whom correspondence should be addressed.

E-mail: risto.laitinen@oulu.fi; Tel: +358 8 553-1611; Fax: +358 8 553-1608

E-mail: heikki.tuononen@jyu.fi; Tel. +358 14 260-2613; Fax +358 14 260-2501

$\dagger$ University of Jyväskylä

$\$$ University of Oulu

$\S$ University of Calgary 


\section{Abstract}

The electronic structures and molecular properties of $\mathrm{S}_{2} \mathrm{~N}_{2}$ as well as the currently unknown chalcogen nitrides $\mathrm{Se}_{2} \mathrm{~N}_{2}$ and $\mathrm{SeSN}_{2}$ have been studied using various ab initio and density functional methods. All molecules share a qualitatively similar electronic structure and can be primarily described as $2 \pi$-electron aromatics having minor singlet diradical character of $6-8 \%$ that can be attributed solely to the nitrogen atoms. This diradical character is manifested in the prediction of their molecular properties, in which coupled cluster and multiconfigurational approaches, as well as density functional methods show the best performance. The conventional ab initio methods RHF and MP2 completely fail to describe these systems. Predictions for the vibrational frequencies, IR intensities, Raman activities, ${ }^{14} \mathrm{~N},{ }^{15} \mathrm{~N}$, and ${ }^{77} \mathrm{Se}$ chemical shifts, as well as singlet excitation energies of $\mathrm{Se}_{2} \mathrm{~N}_{2}$ and $\mathrm{SeSN}_{2}$ have been made. The computed high-level spectroscopic data will be of considerable value in future efforts aimed at the preparation of the conducting polymers $(\mathrm{SeN})_{\mathrm{x}}$ and $(\mathrm{SeNSN})_{\mathrm{x}}$. 


\section{Introduction}

Poly(sulfur nitride), $(\mathrm{SN})_{\mathrm{x}}$, is an inorganic polymer in which alternating nitrogen and sulfur atoms form planar quasi-one-dimensional chains. ${ }^{1}$ One of the many exceptional physical properties it exhibits is good electrical conductivity along the chains. ${ }^{1}$ In addition, the material becomes superconducting below liquid helium temperatures i.e. near $0.3 \mathrm{~K}^{2}{ }^{2}$ In principle, the conductivity of $(\mathrm{SN})_{\mathrm{x}}$ can be increased by either full or partial replacement of sulfur atoms with one of the heavier congeners of group 16, selenium or tellurium. However, the preparation and characterization of heavier chalcogen-bearing analogues of $(\mathrm{SN})_{\mathrm{x}}$ has not been reported.

Although there are several synthetic strategies leading to $(\mathrm{SN})_{\mathrm{x}},{ }^{1}$ the classical route involving the thermal decomposition of $\mathrm{S}_{4} \mathrm{~N}_{4}$ in the presence of silver wool is the method of choice for the formation of good quality crystals of $(\mathrm{SN})_{\mathrm{x}} \cdot{ }^{3}$ The same method cannot, however, be readily applied to the synthesis of $(\mathrm{SeN})_{\mathrm{x}}$ because of the explosive and nonvolatile nature of the obvious precursor $\mathrm{Se}_{4} \mathrm{~N}_{4}$. Therefore, the preparation of heavier chalcogen-bearing analogues of $(\mathrm{SN})_{\mathrm{x}}$ requires the development of new synthetic methods or precursors. ${ }^{4}$

Kelly et al. have outlined a synthetic approach to the preparation of $(\mathrm{SeN})_{\mathrm{x}}$ polymer which utilizes metal complexes of $\mathrm{Se}_{2} \mathrm{~N}_{2}{ }^{8}$ e.g. the tetrabutylammonium salt of $\left(\mu-N, N^{\prime}-\right.$ diselenium dinitride)bis[tribromopalladate(II) $]^{9}$ from which free $\mathrm{Se}_{2} \mathrm{~N}_{2}$ could be released via ligand exchange reactions. A similar pathway has been utilized to generate free $\mathrm{S}_{2} \mathrm{~N}_{2}$

from the adduct with $\mathrm{AlCl}_{3} .{ }^{10} \mathrm{~A}$ subsequent polymerization of the crystallized free $\mathrm{Se}_{2} \mathrm{~N}_{2}$ would then yield the polymer $(\mathrm{SeN})_{\mathrm{x}}$. 
The recent preparation of $1,5-\mathrm{Se}_{2} \mathrm{~S}_{2} \mathrm{~N}_{4}{ }^{11,12}$ might provide a route to the mixed chalcogen-nitrogen polymer $(\mathrm{SeNSN})_{\mathrm{x}}$. Although this compound is explosive under the influence of heat and mechanical stress, it is sufficiently volatile to undergo thermolysis in the presence of silver wool. The formation of the four-membered ring $\mathrm{SeSN}_{2}$ as a $\mathrm{TiCl}_{4}$ adduct has previously been reported by Haas et al. ${ }^{13}$ Free $\mathrm{SeSN}_{2}$ has also been proposed to be an intermediate in the production of $1,5-\mathrm{Se}_{2} \mathrm{~S}_{2} \mathrm{~N}_{4}$ from $\mathrm{Se}(\mathrm{NSO})_{2}{ }^{13,14}$ and in reactions of $\left(\mathrm{Me}_{3} \mathrm{SiNSN}\right)_{2} \mathrm{E}$ with $\mathrm{ECl}_{2}(\mathrm{E}=\mathrm{S}, \mathrm{Se}) .{ }^{12}$ However, neither the crystal structure nor molecular properties of a discrete $\mathrm{SeSN}_{2}$ ring have been determined.

Since all proposed routes to $(\mathrm{SeN})_{x}$ and $(\mathrm{SeNSN})_{x}$ polymers involve $\mathrm{Se}_{2} \mathrm{~N}_{2}$ and $\mathrm{SeSN}_{2}$ ring systems as reaction intermediates, molecular characterization methods capable of confirming the formation of the four-membered rings will play a crucial role in determining whether the synthetic approaches are viable. High-level theoretical calculations can play an important role in providing accurate data regarding the molecular properties of $\mathrm{Se}_{2} \mathrm{~N}_{2}$ and $\mathrm{SeSN}_{2}$ to which the experimental results can then be compared. Currently such data are nonexistent. ${ }^{15}$

A prerequisite for obtaining accurate molecular properties using computational methods is that the chosen theoretical approach is able to give a balanced description of all factors affecting the electronic structure. When considering the four-membered chalcogen-nitrogen rings, this becomes a non-trivial task. Several theoretical studies have attempted to elucidate the uncertainties associated with the electronic structure of $\mathrm{S}_{2} \mathrm{~N}_{2}$ and related species. However, total consensus has yet to be reached.

The bonding in $\mathrm{S}_{2} \mathrm{~N}_{2}$ was first described with four localized $\sigma$-bonds and six delocalized $\pi$-electrons, 1 thus implying some similarity with aromatic structures. ${ }^{18,19}$ As 
opposed to this view, Skrezenek and Harcourt have shown that the primary Lewis-type valence bond (VB) structure for $\mathrm{S}_{2} \mathrm{~N}_{2}$ resembles the spin-paired singlet diradical structure 2 with a long $\mathrm{N} \cdots \mathrm{N}$ bond across the ring. ${ }^{20-23}$ This opinion, however, has been questioned by Gerratt et al. ${ }^{24}$ who used spin-coupled VB theory calculations to show that while the structure is a singlet diradical in nature, the diradical character is solely assigned to the sulfur atoms, 3. More recently Jung et al. ${ }^{25}$ using different ab initio and DFT methods, have shown that $\mathrm{S}_{2} \mathrm{~N}_{2}$ is a closed shell $2 \pi$-electron aromatic with an insignificant amount of diradical character. However, large LUMO occupation numbers indicated the presence of a strong antibonding effect which caused a $7 \%$ reduction to the aromatic character of $\mathrm{S}_{2} \mathrm{~N}_{2}$.

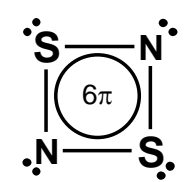

1

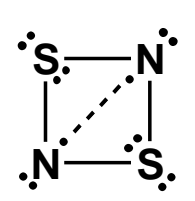

2

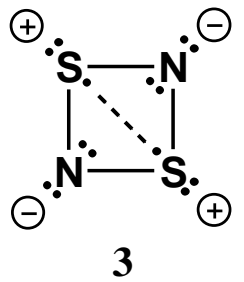

The conclusions of Jung et al. ${ }^{25}$ are for the most part in agreement with our recent high level ab initio analysis of the electronic structure of $\mathrm{S}_{2} \mathrm{~N}_{2}$, as we also found it to be a primarily aromatic system. ${ }^{16}$ Our detailed wave function analysis showed that $\mathrm{S}_{2} \mathrm{~N}_{2}$ possesses $6 \%$ diradical character which could be attributed to the nitrogen atoms. This value is in good agreement with the antibonding effect discussed by Jung et $a .^{25}$ However, they do not directly relate the antibonding effect to the diradical character in their conclusions.

The purpose of the current contribution is two-fold. First, before any further theoretical work is done for $\mathrm{S}_{2} \mathrm{~N}_{2}$ and the related ring systems, it is important to achieve a consensus on the best description of their electronic structures. We consider this to be a 
realistic objective that can be achieved mainly with a theory-based re-evaluation of the previous work. We show here that the chalcogen-nitrogen ring systems $\mathrm{S}_{2} \mathrm{~N}_{2}, \mathrm{Se}_{2} \mathrm{~N}_{2}$ and $\mathrm{SeSN}_{2}$ are all mainly aromatic in nature and have only a small amount (6-8\%) singlet diradical character. However, contrary to the conclusions drawn by Jung et al. ${ }^{25}$ the diradical character is extremely significant to take into account in theoretical calculations. Second, once a clear description of the electronic structure has been established, we will use high level ab initio and DFT methods to reproduce the molecular properties of $\mathrm{S}_{2} \mathrm{~N}_{2}$ and predict those of the currently unknown ring systems $\mathrm{SeSN}_{2}$ and $\mathrm{Se}_{2} \mathrm{~N}_{2}$. The results for $\mathrm{S}_{2} \mathrm{~N}_{2}$ enable comparison to experimental data and therefore ascertain the level of accuracy that can be achieved.

\section{Theoretical Methods}

Calculations were carried out for $\mathrm{S}_{2} \mathrm{~N}_{2}, \mathrm{Se}_{2} \mathrm{~N}_{2}$ and $\mathrm{SeSN}_{2}$. Throughout the work, $\mathrm{S}_{2} \mathrm{~N}_{2}$ and $\mathrm{Se}_{2} \mathrm{~N}_{2}$ molecules were orientated in the xy-plane: nitrogen atoms were located on the $\mathrm{x}$ axis and chalcogen atoms on the y-axis. $\mathrm{SeSN}_{2}$ was constrained to the yz-plane in such a manner that the chalcogen atoms resided on the z-axis. Full point group symmetries $\left(\mathrm{C}_{2 \mathrm{v}}\right.$ or $\mathrm{D}_{2 \mathrm{~h}}$ ) and Dunning's correlation consistent basis sets of triple-zeta quality, cc-pVTZ and aug-cc-pVTZ, were used in all calculations. ${ }^{26}$

Geometries of all molecules were fully optimized in their singlet ground states using several different theoretical methods: RHF, MP $2,{ }^{27} \mathrm{CCSD}, \mathrm{CCSD}(\mathrm{T}),{ }^{28} \mathrm{CAS},{ }^{29}$ and CASPT2. ${ }^{30}$ Two density functionals, $\mathrm{PBEPBE}^{31,32}$ and PBE0 ${ }^{33,34}$ were also used in the optimizations. In CAS optimizations, the active space consisted of full valence space and 
included all possible configurations that arise from the distribution of 22 valence electrons in 11 highest occupied and 5 lowest virtual orbitals i.e. [22,16]-CAS. The active space was considerably reduced in CASPT2 optimizations due to the larger computational cost of the method and the lack of analytical first and second order derivatives. Only MOs that were involved in the most important configurations of $[22,16]-C A S$ wave functions were retained in the active space. Thus, the active space in CASPT2 calculations included only the lowest unoccupied and two highest occupied orbitals i.e. [4,3]-CAS.

Vibrational frequencies, IR intensities, Raman activities, ${ }^{14} \mathrm{~N},{ }^{15} \mathrm{~N}$, and ${ }^{77} \mathrm{Se}$ nuclear magnetic shielding tensors, as well as singlet/triplet excitation energies were calculated for all molecules.

Vibrational frequencies were calculated utilizing all aforementioned methods within the harmonic approximation. For methods for which analytical second derivatives were not implemented, frequencies were calculated using finite differences of energy. All methods except CCSD(T) were used in the calculation of IR intensities whereas Raman activities were calculated only with RHF, MP2, and density functional methods.

Singlet and triplet excitation energies were calculated using TDHF, SOPPA, EOMCCSD, CAS, CASPT2 and TDDFT. In CAS and CASPT2 calculations the active space size was $[22,16]$. First, a state averaged CAS calculation was performed (with equal weights for all states) for the ground state and the lowest eight excited singlet (triplet) states. The resulting orbitals were then used in subsequent CASPT2 calculations in which energies of the excited singlet (triplet) states belonging to the same symmetry were calculated together using equal weights for all states. 
${ }^{14} \mathrm{~N},{ }^{15} \mathrm{~N}$, and ${ }^{77} \mathrm{Se}$ nuclear magnetic shielding tensors were calculated using the GIAO ansatz. ${ }^{35}$ RHF, MP2, and CAS methods, as well as both density functionals were used in the shielding tensor calculations. To facilitate the comparison among different methods, NMR shielding tensors were also calculated for the experimentally characterized parent compounds $\mathrm{S}_{4} \mathrm{~N}_{4}$ and $\mathrm{Se}_{2} \mathrm{~S}_{2} \mathrm{~N}_{4}$. Ammonia and dimethyl selenide were used as references for ${ }^{14} \mathrm{~N},{ }^{15} \mathrm{~N}$, and ${ }^{77} \mathrm{Se} \mathrm{NMR}$ chemical shifts, respectively. However, following the common practice, the reported ${ }^{14} \mathrm{~N}$ and ${ }^{15} \mathrm{~N}$ values are referenced to neat nitromethane $\left[\delta\left(\mathrm{MeNO}_{2}\right)=\delta\left(\mathrm{NH}_{3}\right)+380 \mathrm{ppm}\right]$.

Band gap calculations for the one-dimensional model systems of $\mathrm{S}_{2} \mathrm{~N}_{2}, \mathrm{Se}_{2} \mathrm{~N}_{2}$ and $\mathrm{SeSN}_{2}$ were done using the PBC module of the Gaussian03 program. Pure GGA PBEPBE functional and aug-cc-pVTZ basis set were used in all PBC calculations.

All calculations were carried out using Gaussian 03, ${ }^{36}$ Dalton 1.2.1, ${ }^{37}$ and Molpro $2002.6^{38}$ sets of programs.

\section{Results and Discussion}

\section{The electronic structure of $\mathrm{S}_{2} \mathrm{~N}_{2}$.}

There are two important unanswered questions relating to the electronic structure of $\mathrm{S}_{2} \mathrm{~N}_{2}$ and its heavier chalcogen analogues: What is the amount of singlet diradical character (if any) and should it be attributed to chalcogen or nitrogen atoms in the molecule? Of all the recent papers published on this topic ${ }^{16,20-25}$ only Jung et al..$^{25}$ report that the diradical 
character in $\mathrm{S}_{2} \mathrm{~N}_{2}$ is insignificant. However, their analysis of LUMO occupation numbers shows that the molecule exhibits some strong electron correlations.

The primary evidence by which Jung et $a l .{ }^{25}$ infer that the diradical character in $\mathrm{S}_{2} \mathrm{~N}_{2}$ is not significant is the lack of a symmetry-broken UB3LYP solution. However, this lack of symmetry-broken spin-unrestricted DFT solution cannot be held as a definite proof of a non-existent diradical character because DFT solutions are found to be stable even for some of the obvious diradicals such as ozone whose diradical character has been found to be $26 \%$ by ab initio methods. ${ }^{16}$ In ab initio theory, the instability of the spinrestricted SCF solution is a direct indication of the quality of the wave function, whereas within the DFT framework of electronic structure theory it mirrors the capability of the exchange-correlation functional to describe the electron density with a single Slater determinant comprised of Kohn-Sham (KS) orbitals. If the exact exchange-correlation functional were available, a single Slater determinant of KS orbitals would be adequate to describe even pure diradical systems and, hence, no lower-energy spin-unrestricted solutions would therefore be found.

This was shown to be true by Gritsenko and Baerends ${ }^{39}$ who used an essentially exact KS potential derived from high level ab initio calculations to describe the dissociation of $\mathrm{H}_{2}$. They found that a single Slater determinant represents the noninteracting KS reference system not only in the equilibrium bond distance, but also when the $\mathrm{H}-\mathrm{H}$ bond is significantly stretched. The performance of current exchange-correlation functionals is not as good, since they are unable to reproduce the non-classical contributions to the energy, which leads to incorrect dissociation curves within the restricted scheme. ${ }^{40}$ However, the B3LYP/aug-cc-pVQZ solution first becomes singlet unstable at $\mathrm{r}(\mathrm{H}-\mathrm{H})=2.0 \cdot \mathrm{r}_{\mathrm{o}}$ which corresponds to $19 \%$ diradical character based on the 
[2,2]-CAS wave function at the same internuclear distance. The corresponding GGA functional BLYP performs even slightly better and displays a singlet instability when $\mathrm{r}(\mathrm{H}-\mathrm{H})>2.1 \cdot \mathrm{r}_{\mathrm{o}}$ using the same basis set. The poorer performance of the hybrid functional comes from the inclusion of a constant fraction of the RHF exact exchange, which leads to non-physical delocalized exchange-correlation hole upon bond elongation. ${ }^{40}$

Consequently, the possible diradical character of $\mathrm{S}_{2} \mathrm{~N}_{2}$ should be evaluated based on the stability of the spin-restricted Hartree-Fock SCF solution instead of the corresponding DFT solution. We have recently shown that even at the equilibrium geometry, the RHF wave function of $\mathrm{S}_{2} \mathrm{~N}_{2}$ displays a singlet instability. ${ }^{16}$ Because a symmetry-broken UHF solution can be found, it is perfectly valid to state that the strong electron correlations described by Jung et al. ${ }^{25}$ are a direct consequence of the diradical nature in $\mathrm{S}_{2} \mathrm{~N}_{2}$. A rigorous wave function-based analysis therefore leaves the origin of the electron correlations unquestionable and subsequent analyses of the molecular properties of $\mathrm{S}_{2} \mathrm{~N}_{2}$ (vide infra) show that the proper description of the diradical character becomes essential in theoretical calculations.

Before turning attention to the molecular properties of $\mathrm{S}_{2} \mathrm{~N}_{2}$ and the related heavier chalcogen containing species $\mathrm{SeSN}_{2}$ and $\mathrm{Se}_{2} \mathrm{~N}_{2}$, we seek to answer another open question, whether the diradical character in $\mathrm{S}_{2} \mathrm{~N}_{2}$ should be attributed to nitrogen or to sulfur atoms. Previous VB calculations have come to two different conclusions, ${ }^{20-24}$ whereas our recent MO-theory based wave function analyses indicated that the diradical character of $\mathrm{S}_{2} \mathrm{~N}_{2}$ in its equilibrium geometry can be unquestionably addressed to the nitrogen atoms. ${ }^{16}$ In the following we will present further theoretical evidence based on symmetry-broken spin densities of familiar radicals that supports this interpretation. 
It is clear from elementary quantum mechanics that the spin density associated with a symmetry-broken singlet UHF wave function is non-physical as it does not equal zero at every point in space. For example, in $\mathrm{H}_{2}$ dissociation the UHF solution breaks the inversion symmetry as the $\mathrm{H}-\mathrm{H}$ distance increases and leads to spin polarization where $\alpha$ spin density concentrates on one nucleus and $\beta$-spin density at the other [see Figure 1(a)]. A correct spin density can be restored if we take into account the situation where the spins of the electrons are reversed. This approach to obtain physical spin densities from an ensemble of non-physical spin densities has been used for example in the context of DFT. $^{40}$

(a)

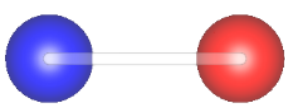

(c)

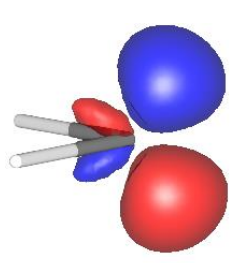

(b)

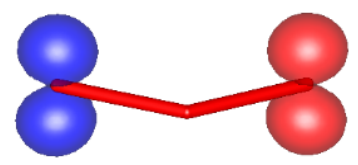

(d)

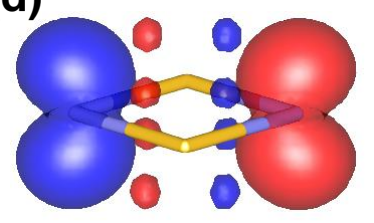

Figure 1. Spin densities of symmetry-broken singlet UHF wave functions of (a) $\mathrm{H}_{2}$ at $\mathrm{r}=$ $2 \cdot \mathrm{r}_{0}$, (b) $\mathrm{O}_{3}$, (c) $\mathrm{CH}_{2}$, and (d) $\mathrm{S}_{2} \mathrm{~N}_{2}$. Red denotes excess $\alpha$-spin density and blue excess $\beta$ spin density.

Despite the non-physical nature of the symmetry-broken spin densities, they usually provide valuable information about the origin of the diradical character. ${ }^{41} \mathrm{~A}$ good illustration of this is the symmetry-broken spin density of $\mathrm{H}_{2}$ at elongated bond lengths, which correctly describes the homolytic dissociation of the bond by localizing one 
electron on each nucleus. Similarly, the symmetry-broken spin density of singlet $\mathrm{O}_{3}$ [Figure 1(b)] mirrors the familiar VB structure 4 in which the two singlet-coupled electrons are localized at the opposite ends of the molecule. The same is also true for singlet methylene, $\mathbf{5}$, whose symmetry-broken spin density shows two electrons with different spins localized above and below of the molecular plane around the central carbon [Figure 1(c)].

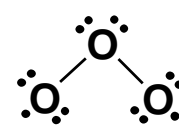

4

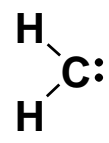

5

In an analogous manner the symmetry-broken singlet UHF spin density of $\mathrm{S}_{2} \mathrm{~N}_{2}$ [Figure 1(d)] shows two singlet-coupled electrons each localized on one of the nitrogen centers. A much smaller amount of the spin density is found on the sulfur atoms. Together with the previous results ${ }^{16,20-24}$ the spin density analysis clearly settles the discussion about the nature of the singlet diradical character in $\mathrm{S}_{2} \mathrm{~N}_{2}$ in favor of the nitrogen-localized VB structure 2. It should, however, be noted that our recent analysis of the $[22,12]$-CAS wave function of $\mathrm{S}_{2} \mathrm{~N}_{2}$ in terms of different Lewis-type VB structures ${ }^{16}$ showed that the VB structure 2 has only $34 \%$ weight in the CAS wave function. Similar conclusion was also obtained by Harcourt et al.. ${ }^{24}$ Although $\mathbf{2}$ is the most significant single Lewis-type VB structure, the combined contribution of the four $2 \pi$-electron VB structures 6-9 exceeds its weight. Hence, as it has been pointed out, ${ }^{24-25} \mathrm{~S}_{2} \mathrm{~N}_{2}$ is primarily an aromatic system with two bonding $\pi$-electrons and strong electron correlation effects. The present work further confirms that the strong electron correlations are static in nature and arise from the nitrogen-centered diradical character in $\mathrm{S}_{2} \mathrm{~N}_{2}$. 


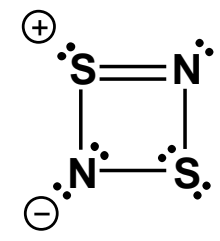

6

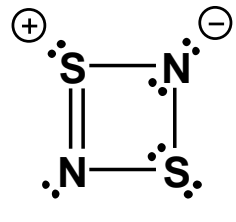

7

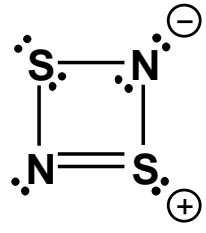

8

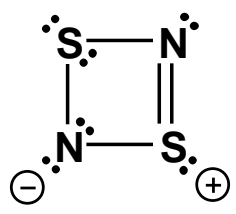

9

Singlet RHF instabilities have also been found for the heavier chalcogen analogues of $\mathrm{S}_{2} \mathrm{~N}_{2}$. Their symmetry-broken UHF spin densities mirror the aforementioned results for $\mathrm{S}_{2} \mathrm{~N}_{2}$. An analysis of the [22,12]-CAS wave function CI coefficients for $\mathrm{SeSN}_{2}$ and $\mathrm{Se}_{2} \mathrm{~N}_{2}$ shows that their diradical characters are $7 \%$ and $8 \%$, respectively. This suggests that the electronic structures of the chalcogen-nitrogen ring systems $\mathrm{S}_{2} \mathrm{~N}_{2}, \mathrm{Se}_{2} \mathrm{~N}_{2}$ and $\mathrm{SeSN}_{2}$ are essentially identical.

\section{Molecular properties of $\mathrm{S}_{2} \mathrm{~N}_{2}, \mathrm{SeSN}_{2}$ and $\mathrm{Se}_{2} \mathrm{~N}_{2}$.}

Table 1 shows the optimized metric parameters of $\mathrm{S}_{2} \mathrm{~N}_{2}, \mathrm{Se}_{2} \mathrm{~N}_{2}$ and $\mathrm{SeSN}_{2}$ calculated at different levels of theory along with the experimental values for free $\mathrm{S}_{2} \mathrm{~N}_{2}{ }^{42,43}$ and the palladium adduct of $\mathrm{Se}_{2} \mathrm{~N}_{2} \cdot{ }^{9}$ Considering the general performance associated with the different theoretical methods, the values in Table 1 show no distinct anomalies. Therefore, no visible indication of the extraordinary electronic nature of these molecules is evident from the calculated geometrical parameters alone. RHF predicts bond lengths that are $0.05 \AA$ too short, whereas MP2 overestimates lengths by nearly the same amount. As expected, coupled cluster, CASPT2, and DFT show the best performance. As observed for the adducts of $\mathrm{S}_{2} \mathrm{~N}_{2},{ }^{10,44,45}$ the coordination of $\mathrm{Se}_{2} \mathrm{~N}_{2}$ to the palladium centers in $\left[\mathrm{Br}_{3} \mathrm{Pd}\left(\mu-\mathrm{N}_{2} \mathrm{Se}_{2}\right) \mathrm{PdBr}_{3}\right]^{2-}$ has very little effect on the $\mathrm{Se}-\mathrm{N}$ bond lengths and the calculated values match well with the experimental ones. ${ }^{10}$ The effect on the bond angles 
is stronger as the $\mathrm{Se}_{2} \mathrm{~N}_{2}$ moiety is distorted noticeably from the idealized structure.

The S-N bond lengths are calculated to be slightly shorter in $\mathrm{SeSN}_{2}$ than in $\mathrm{S}_{2} \mathrm{~N}_{2}$, whereas the corresponding $\mathrm{Se}-\mathrm{N}$ bond lengths are predicted to be longer by an equal amount in $\mathrm{SeSN}_{2}$ than in $\mathrm{Se}_{2} \mathrm{~N}_{2}$. Due to the different size of selenium and sulfur atoms, the geometry of $\mathrm{SeSN}_{2}$ is distorted from the square-planar arrangement in $\mathrm{E}_{2} \mathrm{~N}_{2}$. The ENE' angles are still close to $90^{\circ}$, but the $\angle \mathrm{NSN}$ bond angle is around $97^{\circ}$ and the $\angle$ $\mathrm{NSeN}$ angle is approximately $83^{\circ}$. Interestingly the $\angle \mathrm{NSeN}$ angle is found to be smaller than the $\angle \mathrm{NSN}$ angle. 
Table 1. Optimized Geometries of $\mathrm{S}_{2} \mathrm{~N}_{2}, \mathrm{Se}_{2} \mathrm{~N}_{2}$ and $\mathrm{SeSN}_{2}$ Calculated with Various Methods Using the cc-pVTZ Basis $\mathrm{Set}^{a}$

\begin{tabular}{rlrrrrrrrrr}
\hline & & PBEPBE & PBE0 & RHF & MP2 & CCSD & CCSD(T) & CAS & CASPT2 & exptl. $^{b}$ \\
\hline $\mathrm{S}_{2} \mathrm{~N}_{2}$ & $r(\mathrm{SN})$ & 1.673 & 1.642 & 1.608 & 1.677 & 1.647 & 1.664 & 1.679 & 1.656 & 1.658 \\
& $\angle \mathrm{SNS}$ & 88.6 & 89.1 & 90.1 & 88.2 & 89.3 & 89.0 & 88.9 & 88.7 & 90.4 \\
& $\angle \mathrm{NSN}$ & 91.4 & 90.9 & 89.9 & 91.8 & 90.7 & 91.0 & 91.1 & 91.3 & 89.6 \\
$\mathrm{Se}_{2} \mathrm{~N}_{2}$ & $r(\mathrm{SeN})$ & 1.826 & 1.789 & 1.749 & 1.841 & 1.794 & 1.816 & 1.832 & 1.796 & 1.807 \\
& $\angle \mathrm{SeNSe}$ & 89.9 & 90.5 & 91.8 & 88.9 & 90.7 & 90.3 & 90.1 & 89.7 & 97.9 \\
& $\angle \mathrm{NSeN}$ & 90.1 & 89.5 & 88.8 & 91.1 & 89.3 & 89.7 & 89.9 & 90.3 & 82.1 \\
$\mathrm{SeSN}_{2}$ & $r(\mathrm{SN})$ & 1.647 & 1.615 & 1.561 & 1.674 & 1.616 & 1.637 & 1.647 & 1.634 \\
& $r(\mathrm{SeN})$ & 1.851 & 1.817 & 1.802 & 1.830 & 1.826 & 1.842 & 1.864 & 1.821 \\
& $\angle \mathrm{SNSe}$ & 89.5 & 89.7 & 90.7 & 88.7 & 89.9 & 89.6 & 89.5 & 89.1 \\
& $\angle \mathrm{NSN}$ & 97.4 & 97.1 & 97.4 & 96.8 & 97.0 & 97.1 & 97.7 & 97.2 \\
& $\angle \mathrm{NSeN}$ & 83.7 & 83.5 & 81.3 & 85.9 & 83.1 & 83.6 & 83.4 & 84.6 \\
\hline
\end{tabular}

${ }^{a}$ Bond lengths and bond angles are reported in Ångströms and degrees, respectively. ${ }^{b}$ Experimental data for $\mathrm{S}_{2} \mathrm{~N}_{2}$ and $\mathrm{Se}_{2} \mathrm{~N}_{2}$ is taken from references 43 and 10, respectively. 
Before entering the discussion about second order molecular properties and excitation energies, it is informative to examine the natural orbital occupation numbers (NOONs) obtained from correlated ab initio calculations. As mentioned above, high LUMO occupation numbers can be used to aid in the determination of the amount of diradical character in a molecule. However, NOONs can also be used to identify, whether a multiconfigurational description of the wave function is needed. As Gordon et al. ${ }^{46}$ have shown, the presence of non-physical negative NOONs is a clear indication that the chosen computational approach is not suitable for creating a reliable wave function. For example, when modeling the dissociation of $\mathrm{N}_{2}$ with MP2, negative NOONs appear at $\mathrm{r}=$ $1.2 \AA$ At the same distance the MP2 potential energy curve starts to deviate distinctly from those of multiconfigurational methods as the single determinantal approximation of the wave function loses ground.

We have calculated the MP2 and CCSD NOONs for $\mathrm{S}_{2} \mathrm{~N}_{2}, \mathrm{Se}_{2} \mathrm{~N}_{2}$, and $\mathrm{SeSN}_{2}$ for their equilibrium structures and structures having minimal bond elongation. For all molecules, negative NOONs were found at the MP2 level of theory indicating the breakup of the perturbational approach. Clearly the RHF wave function is not an ideal first order approximation of the true wave function for any of the molecules. By virtue of the infinite-order feature of the coupled cluster methods, they have the ability to handle moderate amounts of static electron correlation. Consequently, all NOONs were found to be positive at the CCSD level. Thus, RHF and MP2 are expected to show unpredictably varying performance when used to calculate the molecular properties of $\mathrm{S}_{2} \mathrm{~N}_{2}, \mathrm{Se}_{2} \mathrm{~N}_{2}$ and $\mathrm{SeSN}_{2}$. 
Vibrational frequencies. The IR active vibrational frequencies of $\mathrm{S}_{2} \mathrm{~N}_{2}$ have been determined by Bragin and Evans, ${ }^{47}$ and Warn and Chapman. ${ }^{48}$ Several authors ${ }^{49,50}$ have already pointed out the apparent inconsistencies in the assignment of vibrational modes by Bragin and Evans and the matter will not be discussed further here. No reliable Raman data have been reported for $\mathrm{S}_{2} \mathrm{~N}_{2}$.

The calculated harmonic vibrational frequencies, IR intensities, and Raman activities for $\mathrm{S}_{2} \mathrm{~N}_{2}, \mathrm{Se}_{2} \mathrm{~N}_{2}$, and $\mathrm{SeSN}_{2}$ are listed in Table 2. As we ${ }^{16}$ and other authors ${ }^{49,51}$ have noted before, the calculated RHF and MP2 frequencies of $\mathrm{S}_{2} \mathrm{~N}_{2}$ show differences of several hundred wave numbers. Scaling the RHF values with an empirical factor of 0.90 improves the match. ${ }^{52}$ However, MP2 results cannot be improved with a uniform scaling factor; and markedly different factors for different normal modes should be used if better agreement is sought with scaling. In addition, MP2 IR intensities and Raman activities deviate noticeably from other values listed in Table 2. Despite the apparent shortcomings of both methods, RHF and MP2 still manage to give a qualitatively accurate description of the frequencies of all normal modes. 
Table 2. Harmonic Vibrational Frequencies $\left[\mathrm{cm}^{-1}\right]$ of $\mathrm{S}_{2} \mathrm{~N}_{2}, \mathrm{Se}_{2} \mathrm{~N}_{2}$ and $\mathrm{SeSN}_{2}$ Calculated at Different Levels of Theory Using the cc-pVTZ Basis Set. ${ }^{a}$

\begin{tabular}{|c|c|c|c|c|c|c|}
\hline $\mathbf{S}_{2} \mathbf{N}_{2}$ & $v_{1}\left(A_{g}\right)$ & $v_{2}\left(A_{g}\right)$ & $v_{3}\left(B_{1 g}\right)$ & $v_{4}\left(B_{1 u}\right)$ & $v_{5}\left(B_{2 u}\right)$ & $v_{6}\left(B_{3 u}\right)$ \\
\hline PBEPBE & $885^{[0,100]}$ & $607^{[0,33]}$ & $897^{[0,34]}$ & $458^{[73,0]}$ & $653^{[1,0]}$ & $752^{[100,0]}$ \\
\hline PBE0 & $974^{[0,100]}$ & $662^{[0,30]}$ & $970^{[0,38]}$ & $490^{[53,0]}$ & $699^{[2,0]}$ & $840^{[100,0]}$ \\
\hline RHF & $1124^{[0,100]}$ & $752^{[0,32]}$ & $1072^{[0,65]}$ & $545^{[34,0]}$ & $659^{[43,0]}$ & $963^{[100,0]}$ \\
\hline MP2 & $829^{[0,100]}$ & $615^{[0,98]}$ & $874^{[0,0]}$ & $467^{[100,0]}$ & $774^{[73,0]}$ & $788^{[6,0]}$ \\
\hline CCSD & $975^{[0,-]}$ & $668^{[0,-\square]}$ & $962^{[0,-]}$ & $489^{[54,0]}$ & $669^{[14,0]}$ & $839^{[100,0]}$ \\
\hline $\operatorname{CCSD}(\mathrm{T})$ & 913 & 637 & 917 & 467 & 654 & 785 \\
\hline CAS & $891^{[0,-]}$ & $620^{[0,-]}$ & $865^{[0,-]}$ & $462^{[74,0]}$ & $604^{[28,0]}$ & $758^{[100,0]}$ \\
\hline CASPT2 & $924^{[0,-]}$ & $648^{[0,-]}$ & $914^{[0,-]}$ & $476^{[69,0]}$ & $687^{[28,0]}$ & $790^{[100,0]}$ \\
\hline exptl. ${ }^{48}$ & - & - & - & 474 & 663 & 795 \\
\hline $\mathrm{Se}_{2} \mathbf{N}_{2}$ & $v_{1}\left(A_{g}\right)$ & $v_{2}\left(A_{g}\right)$ & $v_{3}\left(B_{1 g}\right)$ & $v_{4}\left(B_{1 u}\right)$ & $v_{5}\left(B_{2 u}\right)$ & $V_{6}\left(B_{3 u}\right)$ \\
\hline PBEPBE & $765^{[0,100]}$ & $349^{[0,25]}$ & $730^{[0,23]}$ & $336^{[100,0]}$ & $566^{[8,0]}$ & $611^{[86,0]}$ \\
\hline PBE0 & $843^{[0,100]}$ & $386^{[0,22]}$ & $799^{[0,27]}$ & $358^{[79,0]}$ & $617^{[18,0]}$ & $684^{[100,0]}$ \\
\hline RHF & $980^{[0,100]}$ & $443^{[0,23]}$ & $894^{[0,54]}$ & $399^{[44,0]}$ & $602^{[73,0]}$ & $787^{[100,0]}$ \\
\hline MP2 & $667^{[0,13]}$ & $346^{[0,54]}$ & $685^{[0,100]}$ & $353^{[80,0]}$ & $673^{[100,0]}$ & $668^{[43,0]}$ \\
\hline CCSD & $849^{[0,-]}$ & $393^{[0,-]}$ & $802^{[0,-]}$ & $363^{[78,0]}$ & $603^{[30,0]}$ & $688^{[100,0]}$ \\
\hline $\operatorname{CCSD}(\mathrm{T})$ & 785 & 369 & 751 & 344 & 578 & 635 \\
\hline CAS & $764^{[0,-]}$ & $352^{[0,-]}$ & $730^{[0,-]}$ & $334^{[100,0]}$ & $535^{[51,0]}$ & $609^{[85,0]}$ \\
\hline CASPT2 & $816^{[0,-]}$ & $393^{[0,-]}$ & $762^{[0,-]}$ & $360^{[94,0]}$ & $590^{[15,0]}$ & $652^{[100,0]}$ \\
\hline $\mathrm{SeSN}_{2}$ & $v_{1}\left(A_{1}\right)$ & $V_{2}\left(A_{1}\right)$ & $V_{3}\left(A_{1}\right)$ & $v_{4}\left(B_{1}\right)$ & $V_{5}\left(B_{2}\right)$ & $V_{6}\left(B_{2}\right)$ \\
\hline PBEPBE & $842^{[0,100]}$ & $647^{[1,4]}$ & $440^{[3,31]}$ & $400^{[100,0]}$ & $885^{[36,14]}$ & $626^{[76,14]}$ \\
\hline PBE0 & $928^{[0,100]}$ & $695^{[4,7]}$ & $485^{[3,24]}$ & $427^{[100,0]}$ & $970^{[64,15]}$ & $692^{[99,15]}$ \\
\hline RHF & $1094^{[2,100]}$ & $739^{[36,44]}$ & $525^{[6,2]}$ & $471^{[56,0]}$ & $1122^{[100,16]}$ & $757^{[68,17]}$ \\
\hline MP2 & $755^{[1,21]}$ & $713^{[34,100]}$ & $465^{[2,99]}$ & $412^{[100,0]}$ & $881^{[25,3]}$ & $646^{[4,1]}$ \\
\hline CCSD & $933^{[1,-]}$ & $684^{[12,-]}$ & $484^{[5,-]}$ & $428^{[100,-]}$ & $972^{[67,-]}$ & $694^{[98,-]}$ \\
\hline $\operatorname{CCSD}(\mathrm{T})$ & 867 & 660 & 462 & 408 & 913 & 649 \\
\hline CAS & $843^{[2,-]}$ & $626^{[15,-]}$ & $437^{[9,-]}$ & $401^{[100,-]}$ & $897^{[39,-]}$ & $620^{[75,-]}$ \\
\hline CASPT2 & $889^{[13,-]}$ & $672^{[10,-]}$ & $481^{[1,-]}$ & $419^{[100,-]}$ & $970^{[28,-]}$ & $664^{[97,-]}$ \\
\hline
\end{tabular}

${ }^{a}$ Scaled IR intensities and Raman activities [\%] are reported in square brackets. 
The other methods display a more rational performance. Both PBEPBE and CAS predict too small frequencies for $\mathrm{S}_{2} \mathrm{~N}_{2}$, which mirrors their tendency to overestimate bond lengths (see Table 1). Again coupled cluster, CASPT2, and PBE0 give results, which are in good quantitative agreement with the experimental values. Thus, PBE0, coupled cluster, and CASPT2 are also expected to give the most accurate data for the vibrational frequencies of $\mathrm{SeSN}_{2}$ and $\mathrm{Se}_{2} \mathrm{~N}_{2}$. The data given by these methods can be averaged and used to estimate the observable normal modes. The reported values are expected to be accurate to within $\pm 25 \mathrm{~cm}^{-1}$ because the anharmonicity effects are expected to be very small in the current case.

Figure 2(a) shows the theoretically predicted IR and Raman spectra of $\mathrm{Se}_{2} \mathrm{~N}_{2}$. The three IR allowed fundamentals $v_{4}-v_{6}$ are estimated to occur at $355 \mathrm{~cm}^{-1}, 590 \mathrm{~cm}^{-1}$ and $660 \mathrm{~cm}^{-1}$. The transition at around $590 \mathrm{~cm}^{-1}$ should be considerably less intense than the two other transitions. The corresponding wave numbers for the allowed Raman transitions $v_{1}-v_{3}$ are $822 \mathrm{~cm}^{-1}, 385 \mathrm{~cm}^{-1}$ and $780 \mathrm{~cm}^{-1}$. The Raman activity for the first fundamental is predicted to be more than two times those of the latter two. 

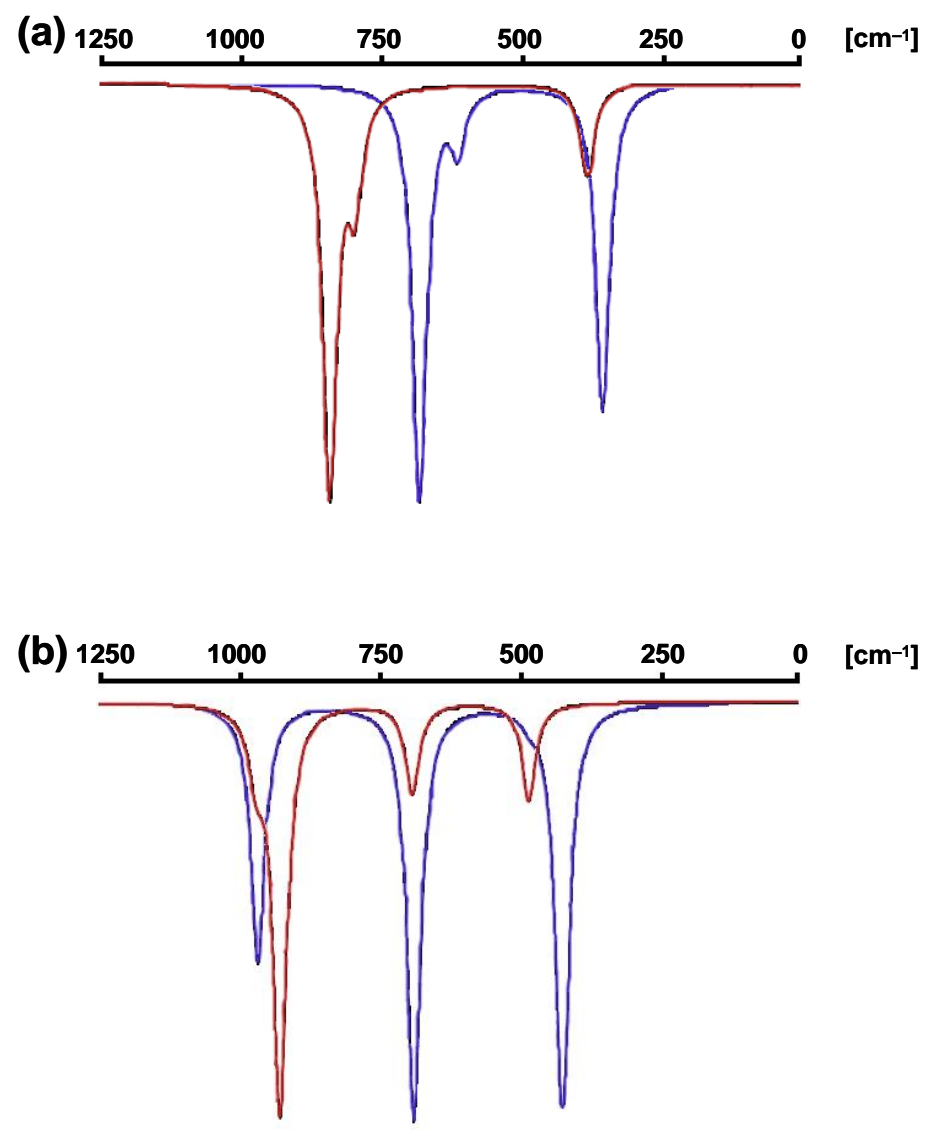

Figure 2. Theoretically predicted IR (blue) and Raman (red) spectra of a) $\mathrm{Se}_{2} \mathrm{~N}_{2}$ and b) $\mathrm{SeSN}_{2}$. The lines are artificially broadened using a Lorentzian line shape and a half-width value of $25 \mathrm{~cm}^{-1}$.

The theoretically predicted IR and Raman spectra of $\mathrm{SeSN}_{2}$ are shown in Figure 2(b). All six fundamentals are both IR and Raman allowed. Calculated IR intensities show that the fundamentals $v_{1}-v_{3}$ should be considerably weaker than $v_{4}-v_{6}$. The three most intense IR transitions are expected to occur at $960 \mathrm{~cm}^{-1}, 675 \mathrm{~cm}^{-1}$ and $420 \mathrm{~cm}^{-1}$. The two normal modes of $\mathrm{SeSN}_{2}$ displaying the largest Raman activities are $v_{1}$ and $v_{3}$ with estimated wave numbers of $905 \mathrm{~cm}^{-1}$ and $480 \mathrm{~cm}^{-1}$, respectively. Two weaker transitions are predicted to occur at $960 \mathrm{~cm}^{-1}$ and $675 \mathrm{~cm}^{-1}$. 
Table 3. NMR Chemical Shifts of Some Chalcogen-Nitrogen Compounds Calculated at Different Levels of Theory Using the cc-pVTZ basis set

\begin{tabular}{llrrrrrr}
\hline & PBEPBE & PBE0 & RHF & MP2 & CAS $^{a}$ & exptl. $^{11}$ \\
\hline${ }^{\mathbf{1 4 , 1 5} N}$ & $\mathrm{~S}_{2} \mathrm{~N}_{2}$ & 63 & 69 & 110 & -104 & 49 & - \\
& $\mathrm{SSeN}_{2}$ & 96 & 108 & 145 & -168 & 72 & - \\
& $\mathrm{Se}_{2} \mathrm{~N}_{2}$ & 160 & 189 & 302 & -479 & 132 & - \\
& $\mathrm{S}_{4} \mathrm{~N}_{4}$ & -237 & -238 & -254 & -259 & - & -256 \\
& $\mathrm{Se}_{2} \mathrm{~S}_{2} \mathrm{~N}_{4}$ & -210 & -211 & -228 & -233 & - & -238 \\
${ }^{77} \mathbf{S e}$ & $\mathrm{SeSN}_{2}$ & 1786 & 1848 & 1911 & 1437 & 1775 & - \\
& $\mathrm{Se}_{2} \mathrm{~N}_{2}$ & 1756 & 1857 & 1991 & 667 & 1728 & - \\
& $\mathrm{Se}_{2} \mathrm{~S}_{2} \mathrm{~N}_{4}$ & 1147 & 1261 & 1251 & 1285 & - & 1418 \\
\hline
\end{tabular}

${ }^{a}$ A full valence CAS space was used in all calculations.

NMR chemical shifts. Table 3 includes the calculated ${ }^{14} \mathrm{~N},{ }^{15} \mathrm{~N}$, and ${ }^{77}$ Se NMR chemical shifts of $\mathrm{S}_{2} \mathrm{~N}_{2}, \mathrm{Se}_{2} \mathrm{~N}_{2}$ and $\mathrm{SeSN}_{2}$ as well as those of $\mathrm{S}_{4} \mathrm{~N}_{4}$ and $1,5-\mathrm{Se}_{2} \mathrm{~S}_{2} \mathrm{~N}_{4}$. It can be seen that the calculated ${ }^{14} \mathrm{~N}$ and ${ }^{15} \mathrm{~N}$ NMR chemical shifts of $\mathrm{S}_{4} \mathrm{~N}_{4}$ and $\mathrm{Se}_{2} \mathrm{~S}_{2} \mathrm{~N}_{4}$ are in excellent agreement with the experimental data. ${ }^{11}$ The calculated ${ }^{77} \mathrm{Se}$ chemical shifts of $\mathrm{Se}_{2} \mathrm{~S}_{2} \mathrm{~N}_{4}$ have slightly larger errors and all methods uniformly predict chemical shifts that are around $200 \mathrm{ppm}$ too small. This is expected since these cage structures exhibit weak transannular E $\cdots \mathrm{E}$ bonding interactions which are known to be difficult to model accurately. ${ }^{53}$ The calculated ${ }^{77} \mathrm{Se}$ shielding is therefore extremely structure-sensitive and even small geometrical displacements induce differences of about $\pm 100 \mathrm{ppm}$ in the calculated shieldings. Therefore we chose to use the experimentally determined geometry of $\mathrm{S}_{4} \mathrm{~N}_{4}$ in all shielding tensor calculations. ${ }^{54-56}$ The crystal structure of $\mathrm{Se}_{2} \mathrm{~S}_{2} \mathrm{~N}_{4}$ cannot, however, be used. It exhibits positional disorder with site occupation factors $c a$. $50 \%$ for selenium in each chalcogen atom position. Therefore, all experimentally determined bond 
parameters reflect only the relative composition of the atomic positions. ${ }^{11}$ For this reason we used the PBE0/cc-pVTZ optimized geometry for $\mathrm{Se}_{2} \mathrm{~S}_{2} \mathrm{~N}_{4}$. This introduces some systematic error into the results which is most likely responsible for the observed homogeneous shift in the calculated ${ }^{77}$ Se shieldings.

A much more non-uniform performance of the different theoretical methods is observed for the calculated shieldings of the four-membered rings. The most distinct feature is the large difference between RHF and MP2 values. Similar results have been obtained previously for the $\mathrm{Se}_{4}{ }^{2+}$ cation whose reported RHF and MP2 ${ }^{77} \mathrm{Se}$ NMR chemical shifts are $3821 \mathrm{ppm}$ and $154 \mathrm{ppm}$, respectively. ${ }^{57}$ The difference becomes larger as the selenium content in the ring increases i.e. in the order $\mathrm{S}_{2} \mathrm{~N}_{2}<\mathrm{SeSN}_{2}<\mathrm{Se}_{2} \mathrm{~N}_{2}$. For $\mathrm{Se}_{2} \mathrm{~N}_{2}$ the RHF-MP2 differences are enormous: $780 \mathrm{ppm}$ and $1324 \mathrm{ppm}$ for ${ }^{14} \mathrm{~N}$ and ${ }^{15} \mathrm{~N}$, and ${ }^{77}$ Se chemical shifts, respectively. In addition, RHF chemical shifts seem to be much better in line with DFT and CAS results than the MP2 values. ${ }^{58}$

The rather conflicting performance of RHF and MP2 is not surprising if one takes into account the singlet diradical character of these molecules. This has already been discussed thoroughly in the context of $\mathrm{Se}_{4}{ }^{2+}$ and other structurally related heterochalcogen cations $\mathrm{S}_{\mathrm{x}} \mathrm{Se}_{4-\mathrm{x}}{ }^{2+}(\mathrm{x}=1-3) .{ }^{16}$ As shown earlier with both wave function and NOON analyses, the RHF wave function is not a good first order approximation of the true wave function for any of the four-membered rings. Consequently, the use of a perturbational approach to calculate electron correlation effects is no longer justifiable and spurious results are obtained. The higher the order of the calculated property is, the more profound the errors become. Both RHF and MP2 give reasonable geometries and qualitatively correct vibrational frequencies, but fail to predict second or third order properties like IR intensities, Raman activities and NMR chemical shifts. 
Interestingly, the PBEPBE and PBE0 results display a similar, albeit much less profound, trend as RHF and MP2. This reflects the fact that hybrid functionals become more and more unsuitable as the diradical character of the molecule increases. A local treatment of the exchange energy is a much better approximation of the true situation and the pure GGA functional therefore performs better. PBEPBE results are also closest to the values obtained with the multiconfigurational CAS method.

As no experimental NMR data are available for $\mathrm{S}_{2} \mathrm{~N}_{2}$, error estimates for the calculated PBEPBE and CAS chemical shifts cannot be readily obtained. An indirect approach is to use the experimental chemical shift of $\mathrm{Se}_{4}{ }^{2+}(1936 \mathrm{ppm})$ as a reference. ${ }^{59}$ The calculated PBEPBE and CAS chemical shifts of $\mathrm{Se}_{4}{ }^{2+}$ are 1906 and $1886 \mathrm{ppm}$, respectively. Both values are slightly smaller than the experimental chemical shift. As all these systems are structurally similar, it is reasonable to assume that the error in the calculated values remains fairly constant. Hence, the ${ }^{77} \mathrm{Se}$ chemical shifts of $\mathrm{SeSN}_{2}$ and $\mathrm{Se}_{2} \mathrm{~N}_{2}$ are expected to occur at $1820 \pm 20 \mathrm{ppm}$ and $1780 \pm 20 \mathrm{ppm}$, respectively. Assuming comparable errors also for nitrogen, the respective ${ }^{14} \mathrm{~N}$ and ${ }^{15} \mathrm{~N}$ chemical shifts of $95 \pm 20$ ppm, $125 \pm 20$ ppm and $185 \pm 20$ ppm for $\mathrm{S}_{2} \mathrm{~N}_{2}, \mathrm{SeSN}_{2}$ and $\mathrm{Se}_{2} \mathrm{~N}_{2}$ can be expected.

Excitation energies. Excitation energy calculations of $\mathrm{S}_{2} \mathrm{~N}_{2}$ have previously been reported at $\mathrm{CI},{ }^{60} \mathrm{MRCI},{ }^{61}$ and TDDFT ${ }^{50}$ correlated levels of theory. The CI results of Jafri et $a l .{ }^{60}$ offer only qualitative insight as the predicted transition energies are overestimated by several eV. Experimentally, the UV/Vis spectrum of $\mathrm{S}_{2} \mathrm{~N}_{2}$ shows one broad band with vibrational fine structure in the range $4.5-5.8 \mathrm{eV} .{ }^{50}$ The shape of this band clearly suggests the presence of two overlapping bands. 
The calculated singlet and triplet excitation energies of $\mathrm{S}_{2} \mathrm{~N}_{2}, \mathrm{Se}_{2} \mathrm{~N}_{2}$ and $\mathrm{SeSN}_{2}$ are presented in Tables 4 and 5, respectively. Only the energies of the lowest eight excited singlet and triplet states are shown. It is only by chance that the lowest eight excited states of $\mathrm{S}_{2} \mathrm{~N}_{2}$ and $\mathrm{Se}_{2} \mathrm{~N}_{2}$ all belong to different symmetries. Excitation energies were also calculated using HF (TDHF) and MP2 (second order polarization propagator approximation, SOPPA) methods. The calculated values, however, turned out to be of little practical use and are therefore omitted from tables. For example, TDHF incorrectly predicted the ground state of $\mathrm{Se}_{2} \mathrm{~N}_{2}$ to be a triplet. Although a SOPPA calculation gave a correct singlet ground state, the triplet excitation energies were still severely underestimated. It is obvious that more elaborate ab initio methods are needed to reach even qualitative accuracy.

The only electric dipole-allowed transitions for $\mathrm{S}_{2} \mathrm{~N}_{2}$ are those to $\mathrm{B}_{1 \mathrm{u}}, \mathrm{B}_{2 \mathrm{u}}$, and $\mathrm{B}_{3 \mathrm{u}}$ symmetric states. However, the calculated CAS, EOM-CCSD and TDDFT oscillator strengths consistently indicated that transition to the first ${ }^{1} \mathrm{~B}_{1 \mathrm{u}}$ state is very low in intensity and will therefore not contribute to the spectrum. In addition, the transition to the $1^{1} \mathrm{~B}_{2 u}$ state is found to be considerably more intense than the transition to the $1^{1} \mathrm{~B}_{3 \mathrm{u}}$ state as calculated oscillator strengths for these states are 0.13 and 0.03 , respectively. These results are in good agreement with earlier findings. ${ }^{50,61}$ 
Table 4. Vertical Singlet Transition Energies $[\mathrm{eV}]$ of $\mathrm{S}_{2} \mathrm{~N}_{2}, \mathrm{Se}_{2} \mathrm{~N}_{2}$ and $\mathrm{SSeN}_{2}$ Calculated at Different Levels of Theory Using the cc-pVTZ Basis Set.

\begin{tabular}{|c|c|c|c|c|c|c|c|c|c|}
\hline & & $1 \mathrm{Ag}$ & $1 B_{3 u}$ & $1 B_{2 u}$ & $1 B_{1 g}$ & 1B1u & $1 B_{2 g}$ & $1 B_{3 g}$ & $1 A_{u}$ \\
\hline \multirow{3}{*}{$\mathrm{S}_{2} \mathrm{~N}_{2}$} & TDPBE0 & 4.95 & 5.25 & 5.25 & 5.92 & 4.41 & 4.37 & 5.61 & 4.37 \\
\hline & CCSD & 5.25 & 5.63 & 5.30 & 6.11 & 4.64 & 4.62 & 5.87 & 4.44 \\
\hline & $\mathrm{CAS}$ & 5.71 & 6.10 & 6.10 & 6.66 & 4.59 & 5.09 & 6.76 & 4.84 \\
\hline \multirow{3}{*}{$\mathrm{Se}_{2} \mathrm{~N}_{2}$} & TDPBE0 & 4.30 & 4.53 & 4.36 & 5.22 & 23.72 & 3.70 & 4.91 & 3.61 \\
\hline & CCSD & 4.23 & 4.67 & 4.29 & 5.18 & 3.58 & 3.73 & 5.06 & 3.51 \\
\hline & CAS & 4.87 & 5.37 & 5.13 & 5.84 & 3.80 & 4.43 & 6.05 & 4.04 \\
\hline \multirow{4}{*}{$\mathrm{SeSN}_{2}$} & TDPBE0 & 4.44 & 4.84 & 3.94 & 5.27 & 4.92 & 5.45 & 3.78 & 4.09 \\
\hline & CCSD & 4.59 & $4-98$ & 4.17 & 5.55 & 5.23 & 5.67 & 3.85 & 4.31 \\
\hline & CAS & 5.03 & 5.75 & 3.98 & 6.39 & 5.64 & 6.15 & 4.17 & 4.87 \\
\hline & CASPT2 & 3.86 & 4.21 & 3.57 & 5.24 & 4.64 & 4.93 & 3.44 & 4.02 \\
\hline
\end{tabular}


Table 5. Vertical Triplet Transition Energies [eV] of $\mathrm{S}_{2} \mathrm{~N}_{2}, \mathrm{Se}_{2} \mathrm{~N}_{2}$ and $\mathrm{SSeN}_{2}$ Calculated at Different Levels of Theory Using the ccpVTZ Basis Set.

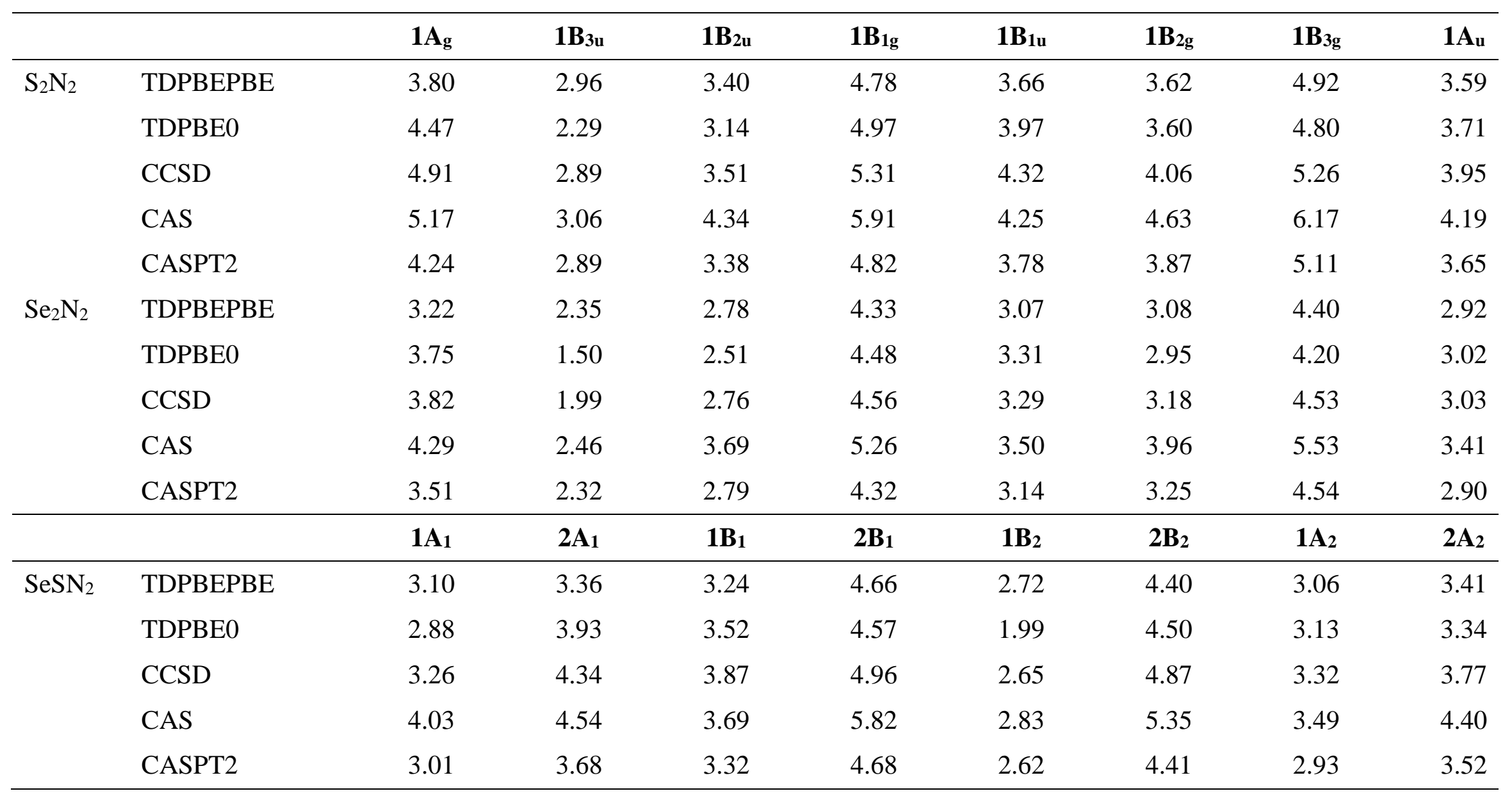


It has been noted earlier ${ }^{50}$ that the addition of diffuse functions to the basis set leads to changes in the energies of the $1^{1} \mathrm{~B}_{3 \mathrm{u}}$ state relative to those of the $1^{1} \mathrm{~B}_{2 u}$ state. As it is possible that some of the excited states might require spatial diffuseness characteristic of Rydberg states, the excitation energies of $\mathrm{S}_{2} \mathrm{~N}_{2}$ were also calculated with the augmented aug-cc-pVTZ basis set. The results were however virtually indistinguishable from those listed in Table 4 and are not tabulated. The addition of diffuse functions resulted in overall lowering of the excitation energies by $0.04 \mathrm{eV}$, but the energy ordering of the states remained unchanged. In particular, we find the $1{ }^{1} \mathrm{~B}_{2 \mathrm{u}}$ state to be always lower in energy than the $1^{1} \mathrm{~B}_{3 \mathrm{u}}$ state. As a result, none of the first eight excited states of $\mathrm{S}_{2} \mathrm{~N}_{2}$ has much Rydberg character. In addition to the basis set, the reported selective energy lowering effect also depends on the method used and the molecular geometry i.e. the relative energy ordering of the nearly degenerate HOMO and HOMO-1 orbitals.

The band maximum in the experimental UV/Vis spectrum of $\mathrm{S}_{2} \mathrm{~N}_{2}$ is at approximately $5.0 \mathrm{eV}(250 \mathrm{~nm}) .{ }^{50}$ It is obvious that the calculated CAS and CCSD singlet excitation energies are overestimated. The same appears to be true also for the TDDFT energies, although the overestimation is not as large. Conversely, the excitation energies are slightly underestimated at the CASPT2 level because calculated $1^{1} B_{3 u}$ and $1^{1} B_{2 u}$ transition energies are both below the experimental band maximum. Both CAS and PBEPBE results are equally close, but on the different sides of the experimental band maximum.

Identical spectral features are predicted for $\mathrm{Se}_{2} \mathrm{~N}_{2}$. The calculated oscillator strengths for the three symmetry-allowed transitions $1{ }^{1} \mathrm{~B}_{1 \mathrm{u}}, 1^{1} \mathrm{~B}_{2 \mathrm{u}}$ and $1^{1} \mathrm{~B}_{3 \mathrm{u}}$ are $0.00,0.12$ and 0.02 , respectively. The band maximum is shifted slightly towards the lower energy end of the spectrum and is expected to occur at $c a .4 .3 \mathrm{eV}(285 \mathrm{~nm})$. The mixed 
chalcogen species $\mathrm{SeSN}_{2}$ shows $\mathrm{C}_{2 \mathrm{v}}$ symmetry, which means that the $\mathrm{A}_{2}$ transitions are dipole forbidden. The calculated oscillator strengths predict one strong $\mathrm{A}_{1}$ transition at around $4.5 \mathrm{eV}(275 \mathrm{~nm})$ and the possible occurrence of two lower intensity transitions slightly above and below $5.0 \mathrm{eV}$.

Taken as a whole, the singlet transition energies in Table 4 show that the excitation energies decrease as the selenium content in the ring increases. The same is also true for the triplet energies (see Table 5). In particular, the singlet-triplet energy gap decreases $0.3 \mathrm{eV}$ with every selenium addition and changes from $3.00 \mathrm{eV}\left(\mathrm{S}_{2} \mathrm{~N}_{2}\right)$ to 2.35 $\mathrm{eV}\left(\mathrm{Se}_{2} \mathrm{~N}_{2}\right)$. This might indicate slightly higher reactivity for the selenium-containing rings.

Crystal structures and band gaps. Disulfur dinitride forms monoclinic crystals, space group is $P 2{ }_{1} / c$, with two $\mathrm{S}_{2} \mathrm{~N}_{2}$ molecules per unit cell. ${ }^{43}$ The crystal structure shows a herring-bone pattern characteristic of closest packing molecular crystals of planar molecules. Along the crystallographic $a$ axis, there is a relative short intermolecular $\mathrm{S} \cdots \mathrm{N}$ contact of $2.889 \AA$. The other $\mathrm{S} \cdots \mathrm{N}$ distances are much longer (mean value of $3.282 \AA$; c.f. $\mathrm{S} \cdots \mathrm{N}$ van der Waals distance $3.35 \AA$ ). The crystals of $\mathrm{S}_{2} \mathrm{~N}_{2}$ are originally colorless, which indicates the existence of a band gap greater than $3.2 \mathrm{eV}$. Theoretical calculations have come to similar conclusions; $\mathrm{S}_{2} \mathrm{~N}_{2}$ has been described as an indirect-gap semiconductor whose energy gap is found to be close to $3 \mathrm{eV} \cdot{ }^{62-64}$ Upon polymerization, the crystals turn an intense dark blue color. Over time the blue color fades and the crystals become a lustrous golden color, indicating the formation of a $(\mathrm{SN})_{\mathrm{x}}$ polymer.

To determine the band gaps for the heavier chalcogen analogues of $\mathrm{S}_{2} \mathrm{~N}_{2}$, at least a one-dimensional model of their crystal structure is needed. For this reason, the 
geometries of the weakly bonded dimers were optimized using the PBE0/aug-cc-pVTZ method. The structure of $\mathrm{S}_{2} \mathrm{~N}_{2} \cdots \mathrm{S}_{2} \mathrm{~N}_{2}$ was found to be remarkably close to the geometry of the unit in the crystal structure, as the calculated intermolecular $\mathrm{S} \cdots \mathrm{N}$ distance was found to be $2.881 \AA$. It can therefore be concluded that electrostatic, bond dipole forces are predominantly responsible of the crystal structure geometry. The corresponding intermolecular Se $\cdots \mathrm{N}$ distance in the selenium analogue was found to be $2.685 \AA$; in good agreement with change in the electronegativity of the chalcogen atom. Similarly, the $\mathrm{S} \cdots \mathrm{N}$ and $\mathrm{Se} \cdots \mathrm{N}$ distances in the optimized mixed chalcogen dimer $\mathrm{SeSN}_{2} \cdots \mathrm{SeSN}_{2}$ were $2.902 \AA$ and $2.684 \AA$. From these three structures, the translational vectors needed for the creation of one-dimensional model systems can be obtained.

Band gap energies were then calculated for all one-dimensional model systems using the pure GGA PBEPBE functional and the aug-cc-pVTZ basis set. The indirect band gap of $\mathrm{S}_{2} \mathrm{~N}_{2}$ was calculated to be $3.32 \mathrm{eV}$, which is in excellent agreement with earlier results. ${ }^{62-64}$ This gap corresponds to a wavelength of $370 \mathrm{~nm}$. The corresponding band gaps for $\mathrm{SeSN}_{2}$ and $\mathrm{Se}_{2} \mathrm{~N}_{2}$ were found to be $2.50 \mathrm{eV}(485 \mathrm{~nm})$ and $2.20 \mathrm{eV}$ (555 $\mathrm{nm}$ ), respectively. Thus, crystals of $\mathrm{SeSN}_{2}$ and $\mathrm{Se}_{2} \mathrm{~N}_{2}$ are predicted to be orange-yellow and red, respectively. In agreement with the aforementioned results for excitation energies, the band gap energy decreases as the selenium content in the ring increases.

\section{Conclusions}

The electronic structures and molecular properties of $\mathrm{S}_{2} \mathrm{~N}_{2}$ as well as the currently unknown chalcogen nitrides $\mathrm{Se}_{2} \mathrm{~N}_{2}$ and $\mathrm{SeSN}_{2}$ have been studied using various ab initio and density functional methods. All molecules share a qualitatively similar electronic 
structure and can be described as $2 \pi$-electron aromatic systems. The existence of symmetry-broken spin-unrestricted HF solutions suggests that the strong electron correlation effects exhibited by the $\mathrm{S}_{2} \mathrm{~N}_{2}, \mathrm{Se}_{2} \mathrm{~N}_{2}$ and $\mathrm{SeSN}_{2}$ ring systems are static in nature and are a direct consequence of their intrinsic minor singlet diradical character. This effect reduces their aromaticity by $6-8 \%$. Together with the previous results, the spin-density analyses provided in this work further confirm that the diradical nature can be unquestionably attributed to nitrogen rather than to sulfur atoms.

Although the singlet diradical nature of $\mathrm{S}_{2} \mathrm{~N}_{2}, \mathrm{Se}_{2} \mathrm{~N}_{2}$ and $\mathrm{SeSN}_{2}$ is not a dominant effect in their wave functions and does not, therefore, exclusively determine their reactivity, it imposes strict requirements on the theoretical methods used in the calculation of their second and higher order molecular properties. This has been demonstrated by wave function and natural orbital occupation number analyses, as well as by comparison of results calculated at different levels of theory. Spurious results are obtained for all present systems, if the methods are incapable of describing their diradical character. Of the conventional ab initio methods, RHF and Møller-Plesset perturbation theory (in all orders) completely fail to describe the electronic structures. The use of a pure GGA density functionals over their hybrid counterparts is preferred, as the employment of a constant fraction from the exact RHF exchange leads to non-physical delocalized exchange-correlation holes in the current case.

Predictions for the vibrational frequencies, IR intensities, Raman activities, and ${ }^{14} \mathrm{~N},{ }^{15} \mathrm{~N}$ and ${ }^{77} \mathrm{Se}$ chemical shifts, as well as singlet excitation energies of $\mathrm{Se}_{2} \mathrm{~N}_{2}$ and $\mathrm{SeSN}_{2}$ have been made by using the results from the theoretically most reliable coupled cluster, CASPT2 and DFT methods. The computed high-level spectroscopic data for $\mathrm{Se}_{2} \mathrm{~N}_{2}$ and $\mathrm{SeSN}_{2}$ will be of considerable value in efforts aimed at the preparation of these 
precusors and, ultimately, the conducting polymers $(\mathrm{SeN})_{\mathrm{x}}$ and $(\mathrm{SeNSN})_{\mathrm{x}}$.

Acknowledgement. Financial support from the Academy of Finland, the Ministry of Education in Finland, and Helsingin Sanomain 100-vuotissäätiö is gratefully appreciated.

H. M. T thanks A. Armstrong for helpful discussions about the manuscript. 


\section{References and Notes}

(1) See Banister, A. J.; Gorrell, I. B. Adv. Mater. 1998, 10, 1415 and references therein.

(2) Greene, R. L.; Street, G. B.; Suter, L. J. Phys. Rev. Lett. 1975, 34, 577.

(3) Walatka, V. V. Jr.; Labes, M. M.; Perlstein, J. H. Phys. Rev. Lett. 1973, 31, 1139.

(4) Other attempts to prepare the heavier chalcogen analogues of $(\mathrm{SN})_{\mathrm{x}}$ have also been reported. All methods have, however, proven unsuccessful due to the nonexistence of suitable selenium-nitrogen precursors or the different chemistries that the selenium analogues of the known sulfur-nitrogen precursors display. ${ }^{5-7}$

(5) Klapötke, T. M. Studies in Inorganic Chemistry 14: The Chemistry of Inorganic Ring Systems, Ed. Steudel, R., Elsevier: Netherlands, 1992, p. 415.

(6) Dehnicke, K.; Schmock, E.; Koehler, K. F.; Frenking G. Angew. Chem., Int. Ed. Engl. 1991, 30, 577.

(7) Siivari, J.; Chivers, T.; Laitinen, R. Angew. Chem., Int. Ed. Engl. 1992, 31, 1518.

(8) Kelly, P. F.; Slawin, A. M. Z. Angew. Chem., Int. Ed. Engl. 1995, 34, 1758.

(9) Aucott, S. M.; Dale, S. H.; Elsegood, M. R. J.; Holmes, K. E.; James, S. L. M.; Kelly, P. F. Acta Cryst. 2004, C60, m643.

(10) Roesky, H. W.; Anhaus, J. Chem. Ber. 1982, 115, 3682.

(11) Maaninen, A.; Laitinen, R. S.; Chivers, T.; Pakkanen, T. A. Inorg. Chem. 1999, 38,3450 .

(12) Konu, J.; Maaninen, A.; Paananen, K.; Ingman, P.; Laitinen, R. S.; Chivers, T.; 
Valkonen, J. Inorg. Chem. 2002, 41, 1430.

(13) Haas, A.; Kasprowski, J.; Angermund, K.; Betz, P.; Krüger, C.; Tsay, Y.-H.; Werner, S. Chem. Ber. 1991, 124, 1895.

(14) Haas, A.; Pryka, M. Chem. Ber. 1995, 128, 11.

(15) In addition to our recent contribution, ${ }^{16}$ the molecular geometry of $\mathrm{Se}_{2} \mathrm{~N}_{2}$ has only been discussed once ${ }^{17}$ and no theoretical data have been reported for $\mathrm{SeSN}_{2}$.

(16) Tuononen, H. M.; Suontamo, R. S.; Valkonen, J.; Laitinen, R. S. J. Phys. Chem. A 2004, 180,5670 .

(17) Mercero, J. M.; Lopez, X.; Fowler, J. E.; Ugalde, J. M. J. Phys. Chem. A 1997, $101,5574$.

(18) Adkins, R. R.; Turner, A. G. J. Am. Chem. Soc. 1978, 100, 1383.

(19) Jafri, J. A.; Newton, M. D.; Pakkanen, T. A.; Whitten, J. L. J. Chem. Phys. 1977, $66,5167$.

(20) Skrezenek, F. L.; Harcourt, R. D. J. Am. Chem. Soc. 1984, 106, 3934.

(21) Harcourt, R. D.; Skrezenek, F. L. J. Mol. Struct. (Theochem) 1987, 151, 203.

(22) Harcourt, R. D.; Klapötke, T. M.; Schulz, A.; Wolynec, P. J. Phys. Chem. A 1998, $102,1850$.

(23) Klapötke, T. M.; Li. J.; Harcourt, R. D. J. Phys. Chem. A 2004, 108, 6527.

(24) Gerratt, J.; McNicholas, S. J.; Karadakov, P. B.; Sironi, M.; Raimondi, M.; Cooper, D. L. J. Am. Chem. Soc. 1996, 118, 6472.

(25) Jung, Y.; Heine, T.; Schleyer, P. v. R.; Head-Gordon, M. J. Am. Chem. Soc. 2004, 
126,3132 .

(26) The basis sets were used as they are referenced in the EMSL basis set library: Extensible Computational Chemistry Environment Basis Set Database, http://www.emsl.pnl.gov/forms/basisform.html. Site accessed November 2004.

(27) Møller, C.; Plesset, M. S. Phys. Rev. 1934, 46, 618.

(28) Raghavachari, K.; Trucks, G. W.; Pople, J. A.; Head-Gordon, M. Chem. Phys. Lett. 1989, 157, 479.

(29) Roos. B. O.; Taylor, P. R.; Siegbahn, P. E. M. Chem. Phys. 1980, 48, 157.

(30) Roos, B. O.; Andersson, K.; Fülscher, M. P.; Malmqvist, P.-Å.; Serrano-Anders, K.; Pierloot, K.; Merchan, M. Adv. Chem. Phys. 1996, 93, 216.

(31) Perdew, J. P.; Burke K.; Ernzerhof, M. Phys. Rev. Lett. 1996, 77, 3865.; ibid. 1997, 78, 1396.

(32) Perdew, J. P.; Ernzerhof, M.; Burke, K. J. Chem. Phys., 1996, 105, 9982.

(33) Ernzerhof, M.; Perdew, J. P.; Burke, K. Int. J. Quantum Chem. 1997, 64, 285.

(34) Ernzerhof, M.; Scuseria, G. E. J. Chem. Phys. 1999, 110, 5029.

(35) Ditchfield, R. Mol. Phys. 1974, 27, 789.

(36) Frisch, M. J.; Trucks, G. W.; Schlegel, H. B.; Scuseria, G. E.; Robb, M. A.; Cheeseman, J. R.; Montgomery, Jr., J. A.; Vreven, T.; Kudin, K. N.; Burant, J. C.; Millam, J. M.; $\quad$ Iyengar, S. S.; Tomasi, J.; Barone, V.; Mennucci, B.; Cossi, M.; Scalmani, G.; Rega, N.; Petersson, H. G.; Nakatsuji, A.; Hada, M.; Ehara, M.; Toyota, K.; Fukuda, R.; Hasegawa, J.; Ishida, M.; Nakajima, T.; Honda, Y.; Kitao, O.; Nakai, H.; Klene, M.; Li, X.; Knox, J. E.; Hratchian, H. P. B.; Cross, J.; 
Adamo, C.; Jaramillo, J.; Gomperts, R.; Stratmann, R. E.; Yazyev, O.; Austin, A. J.; Cammi, R.; Pomelli, C.; Ochterski, J. W.; Ayala, P. Y.; Morokuma, K.; Voth, G. A.; Salvador, P.; Dannenberg, J. J.; Zakrzewski, V. G.; Dapprich, S.; Daniels, A. D.; Strain, M. C.; Farkas, O.; Malick, D. K.; Rabuck, A. D.; Raghavachari, K.; Foresman, J. B.; Ortiz, J. V.; Cui, Q.; Baboul, A. G.; Clifford, S.; Cioslowski, J.; Stefanov, B. B.; Liu, G.; Liashenko, A.; Piskorz, P.; Komaromi, I.; Martin, R. L.; Fox, D. J.; Keith, T.; Al-Laham, M. A.; Peng, C. Y.; Nanayakkara, A.; Challacombe, M.; Gill, P. M. W.; Johnson, B.; Chen, W.; Wong, M. W.; Gonzalez, C.; Pople, J. A., Gaussian 03, Revision C.02, Inc., Wallingford CT, 2004.

Dalton, a molecular electronic structure program, Release 1.2.1. (2001), Helgaker, T.; Jensen, H. J. Aa.; Joergensen, P.; Olsen, J.; Ruud, K.; Aagren, H.; Auer, A.A.; Bak, K.L.; Bakken, V.; Christiansen, O.; Coriani, S.; Dahle, P.; Dalskov, E. K.; Enevoldsen, T.; Fernandez, B.; Haettig, C.; Hald, K.; Halkier, A.; Heiberg, H.; Hettema, H.; Jonsson, D.; Kirpekar, S.; Kobayashi, R.; Koch, H.; Mikkelsen, K. V.; Norman, P.; Packer, M. J.; Pedersen, T. B.; Ruden, T. A.; Sanchez, A.; Saue, T.; Sauer, S. P. A.; Schimmelpfennig, B.; Sylvester-Hvid, K. O. P.; Taylor, R.; Vahtras, O., 2001.

Molpro 2002.6 is a package of ab initio programs designed by Werner, H.-J. and Knowles, P.J. The authors are Amos, R.D.; Bernhardsson, A.; Berning, A.; Celani, P.; Cooper, D.L.; Deegan, M.J.O.; Dobbyn, A.J.; Eckert, F.; Hampel, C.; Hetzer, G.; Knowles, P.J.; Korona, T.; Lindh, R.; Lloyd, A.W.; McNicholas, S.J.; Manby, F.R.; Meyer, W.; Mura, M.E.; Nicklaß, A.; Palmieri, P.; Pitzer, R.; Rauhut, G.; Schütz, M.; Schumann, U.; Stoll, H.; Stone A. J.; Tarroni, R.; 
Thorsteinsson, T.; Werner, H.-J..

(39) Gritsenko, O. V.; Baerends, E. J. Theor. Chem. Acc. 1997, 96, 44.

(40) Koch, W.; Holthausen, M. C. A Chemist's Guide to Density Functional Theory, $2^{\text {nd }}$ edition, VCH: Weinheim, 2001, pp. 41-64.

(41) Jung, Y.; Head-Gordon, M. Chem. Phys. Chem. 2003, 4, 522.

(42) Mikluski, C. M.; Russo, P. J.; Saran, M. S.; MacDiarmid, A. G.; Garito, A. F.; Heeger, A. J. J. Am. Chem. Soc. 1975, 97, 6358.

(43) Cohen, M. J.; Garito, A. F; Heeger, A. J.; MacDiarmid, A. G.; Mikluski, C. M.; Saran, M. S.; Kleppinger, J. J. Am. Chem. Soc. 1976, 98, 3844.

(44) Patton, R. L.; Raymond, K. N. Inorg. Chem. 1969, 8, 2426.

(45) Thewalt, U.; Burger, M. Angew. Chem., Int. Ed. Engl. 1982, 21, 634.

(46) Gordon, M. S.; Schmidt, M. W.; Chaban, G. M.; Glaesemann, K. R.; Steevens, W. J.; Gonzalez, C. J. Chem. Phys. 1999, 110, 4199.

(47) Bragin, J.; Evans, M. V. J. Chem. Phys. 1968, 51, 268.

(48) Warn, J. R. W.; Chapman, D. Spectrochim. Acta 1966, 22, 1371.

(49) Somasundram, K.; Handy, N. C. J. Phys. Chem. 1996, 100, 17485.

(50) Bridgeman, A. J.; Cunningham, B. Spectrochim. Acta 2004, A60, 471.

(51) Janssen, R. A. J. J. Phys. Chem. 1993, 97, 6384.

(52) This factor takes into account the systematic errors that arise from the neglect of both electron correlation and anharmonicity effects.

(53) For example, see the discussion in Chung G.; Duckhwan, L. J. Mol. Struct. 
(Theochem), 2002, 582, 85.

(54) Clark, D. J. Chem. Soc. 1952, 1615.

(55) Sharmam B. D.; Donohue, J. Acta Crystallogr. 1963, 16, 891.

(56) DeLucia, M. L.; Coppens, P. Inorg. Chem. 1978, 17, 2336.

(57) Bühl, M.; Thiel, W.; Fleischer, U.; Kutzelnigg, W. J. Phys. Chem. 1995, 99, 4000.

(58) The RHF and MP2 chemical shifts were also calculated using the PBE0/cc-pVTZ optimized geometry in order to assess the effect of the geometry on the calculated chemical shifts. This did not, however, improve the agreement with the DFT and CAS values. In addition, the RHF-MP2 differences still remained prohibitively large.

(59) Collins, M. J.; Gillespie, R. J.; Sawyer, J. F.; Schrobilgen, G. J. Inorg. Chem. 1986, 25, 2053.

(60) Jafri, J. A.; Newton, M. A.; Pakkanen, T. A.; Whitten, J. L. J. Chem. Phys. 1977, $66,5167$.

(61) Palmer, M. H.; Guest, M. F. Chem. Phys. 1986, 110, 187.

(62) Batra, I. P.; Ciraci, S.; Rudge, W. E.; Phys. Rev. B. 1977, 15, 5858.

(63) Kurmaev, E. Z.; Poteryaev, A. I.; Anisimo, V. I.; Karla I.; Mowes A.; Schneider, B.; Neumann, M.; Ederer, D. L.; Lyubovskaya, R. N. Physica 1999, C321, 191.

(64) Mei, C. J.; Monkhorst, H. J.; Bartlett, R. J. Z. Phys. B 1996, 101, 73. 